\title{
VII CONFERENCIA NACIONAL DA ORDEM DOS ADVOGADOS DO BRASIL
}

\author{
TEMA: O ESTADO DE DIREITO - AS TESES DISCUTIDAS - \\ A DECLARAÇÃO DOS ADVOGADOS
}

No período de 7 a 12 de maio de 1978, na cidade de Curitiba, foi realizada, com remarcada repercussão nos meios jurídicos e políticos de todo o País, a VII CONFERENCIA NACIONAL DA ORDEM DOS ADVOGADOS DO BRASIL.

O certame, que contou com a participação de mais de mil e quinhentos inscritos, dentre advogados militantes e estudantes de Direito, foi convocado pelo Prof. Raymundo Faoro, presidente do Conselho Federal da $O A B$, nos seguintes termos:

"A convocação aos advogados brasileiros para que compareçam e prestigiem a VII Conferência Nacional da Ordem dos Advogados do Brasil não poderia, no atual momento histórico, ter outro tema, senão o Estado de Direito. Será necessário que os advogados, ao espelhar a consciência jurídica do país, reflitam sobre a realidade presente e ofereçam a contribuição de sua inteligência para ordenar, sob o império da lei, as instituições abaladas em profunda crise de legitimidade.

Ao traçar os rumos da mudança social e jurídica, invocamos a tradição brasileira, na sua expressão mais alta, lembrando o nome do nosso maior constitucionalísta do século passado, José Antônio Pimenta Bueno, Marquês de São Vicente, cujo centenário de falecimento transcorre neste ano de 1978. Colocamos a VII Conferência, voltada ao estudo militante, também sob o patrocínio de outra recordação, timbrada no trigésimo aniversário da Declaração Universal dos Direitos do Homem, a cujos princípios se devotaria $\mathrm{Pi}$ menta Bueno, se vivesse, como afirma sua obra legislativa pela emancipação dos escravos. Para ele, o Estado de Direito deverá escudar-se na Constituição, a inspiração dos direitos do homem e das instituições - "nossa arca da aliança em nossas tempestades e perigos", ontem, hoje e amanhã". 
O tema central da Conferência versou sobre O ESTADO DE DIREITO. As figuras de José Antonio Pimenta Bueno, Marquês de São Vicente, e Hugo Simas - protótipos da cultura jurídica brasileira - constituiram o símbolo e a expressão de nossas melhores tradições jurídicas, como patronos do importante e significativo conclave. Foi o seguinte o programa observado:

Dia 7 - Domingo

20,00 hs

Sessão Solene de Instalação no Teatro Guaíra

\section{Dia 8 - Segunda-feira}

9,00 às 12,00 hs Reunião de Comissões Especiais

14,30 às 18,30 hs Reunião de Comissões Especiais

Dia 9 - Terça-feira

9,00 às 12,00 hs Reunião de Comissões Especiais

14,30 às 18,30 hs Reunião de Comissões Especiais

Dia 10 - Quarta-feira

9,00 às 12,00 hs Reunião de Comissões Especiais

14,30 às 18,30 hs Reunião de Comissõ̃es Especiais

Dia 11 - Quinta-feira

14,30 às 18,30 hs Painel - Estado de Direito

Dia 12 r Sexta-feira

9,00 às 12,00 hs Sessão Plenária

14,30 às 17,30 hs Sessão Plenária e Encerramento

$21,00 \mathrm{hs}$ Jantar de Confraternização

\section{PAINEL - ESTADO DE DIREITO}

Presidente:

MIGUEL SEABRA FAGUNDES

Secretário:

JOSÉ JÚLIO CAVALCANTE CARVALHO

Relatores:

BRASIL PINHEIRO MACHADO

EDUARDO ROCHA VIRMOND

FRANCISCO CORREA WEFFORT

OLIVEIROS DA SILVA FERREIRA

ORLANDO CARVALHO

TERCIO SAMPAIO FERRAZ 
Os trabalhos das Comissões Especiais tiveram como local as dependências da Faculdade de Direito da Universidade Federal do Paraná, cedidas por seu Diretor Prof. Othelo Werneck Lopes; as sessões plenárias e o Painel, o auditório da Reitoria da U.F.Pr..

A sessão solene de abertura foi realizada no auditório do Teatro Guaíra, com a presença de altas autoridades estaduais e federais, destacando-se o Governador do Estado Jayme Canet Junior, que falou na ocasião, e o Dr. Luiz Rafael Mayer, Consultor Geral da República, como representante do Presidente General Ernesto Geisel. Compareceram também à sessão inaugural o Senador Petrônio Portela, Presidente do Congresso Nacional, o Deputado Marco Antonio Maciel, presidente da Câmara dos Deputados e o Prof. Ocyron Cunha, Reitor da U.F.Pr. e representando o Ministro da Educação e Cultura.

Usaram da palavra, no ato, o Prof. Haroldo Valadão, o Prof. Raymundo Cândido, o dr. Eduardo Rocha Virmond, presidente da Ordem dos Advogados do Brasil, Seção do Paraná, e o Prof. Raymundo Faoro, presidente do Conselho Federal da OAB. O Auditório do Teatro Guaíra estava repleto e se notava no ambiente intensa vibração popular. A Banda da Polícia Militar do Estado abriu a solenidade com a execução do Hino Nacional, executando ao final o Hino do Paraná.

Este o temário, com os respectivos relatores:

\section{ESTADO DE DIREITO}

1. CAIO MÁRIO DA SILVA PEREIRA

Direitos Humanos Conceito Abstrato e Conceito Realista.

2. FRANCISCO DE ASSIS SERRANO NEVES

As Garantias do Processo Penal no Estado de Direito.

3. VIRGÍLIO LUIZ DONNICI

Criminalidade e Estado de Direito

4. MARIA BERNARDETTE NEVES PEDROSA

Estado de Direito e Segurança Nacional

5. NELSON NOGUEIRA SALDANHA

Estado de Direito e Ordem Política

6. SERGIO BERMUDES

Estado de Direito e Direito de Petição

7. GOFREDO DA SILVA TELLES JUNIOR

O Estado de Sítio e as Outras Salvaguardas 
8. ALBERTO GOMES DA ROCHA AZEVEDO

A Formação Profissional e a Militância Advocatícia como Garantia do Estado de Direito

9. NEY LOPES DE SOUZA

As Limitações Constitucionais do Direito Econômico

10. PONTES DE MIRANDA

Habeas-Corpus

11. ALCIDES MUNHOZ NETO

O Estado de Direito e a Segurança Nacional

12. JOSÉ LAMARTINE CORREA DE OLIVEIRA e FRANCISCO JOSE FERREIRA MUNIZ

O Estado de Direito e os Direitos da Personalidade

13. EGAS DIRCEU MONIZ DE ARAGÃO

O Estado de Direito e o Direito de Ação (A Extensão do seu Exercício)

14. RUBENS REQUIÃO

A Função Social da Empresa no Estado de Direito

15. FRANCISCO ACCIOLY FILHO

O Direito ao Casamento e à sua Dissolução entre os Direitos Fundamentais do Indivíduo.

16. EVARISTO DE MORAIS FILHO

Direito do Trabalho no Estado de Direito

17. OSCAR DIAS CORREA

A Emergência Constitucional no Estado de Direito

18. ARNOLDL WALD

Mandado de Segurança e Ação Popular no Estado de Direito

19. MOACYR VELLOSO CARDOSO DE OLIVEIRA

Previdência Social do Advogado

20. VICTOR NUNES LEAL

Representação de Inconsiltucionalidade perante o Supremo Tribunal Federal: Um Aspecto Inexplorado

21. MIGUEL REALE JUNIOR

Estado de Direito e Tecnocracia

22. DARCY PAULILLO DOS PASSOS e

FERNANDO HENRIQUE MENDES DE ALMEIDA

Conteúdo Social dos Direitos Humanos e o Estado de Direito

23. ALCIDES ABREU

Estado de Direito: Essência e Circunstância 
24. EVANDRO LINS E SLVA

Reforma Estrutural do Poder Judiciário como Garantia dos Direitos do Povo

25. JOSÉ CARLOS BARBOSA MOREIRA

A Motivação dqa Sentença como Garantia Inerente ao Estado de Direito.

26. NELSON DE SOUSA SAMPAIO

O Estado de Direito como Estrutura Política. Seu Conceito e Características.

27. BALTHAZAR GAMA BARBOSA

O Poder Judiciário no Estado de Direito

28. RUY DE SOUZA

A Missão do Advogado nas Crises Institucionais

29. GERALDO ATALIBA

Limites Constitucionais do Dercreto-Lei em Matéria Tributária

Foram ainda discutidas, na Conferência, na categoria de avulsas, as seguintes teses:

ADA PELLEGRINI GRINOVER

A Tutela Jurisdicional dos Intereses Difusos.

RAPHAEL DE ALMEDA MAGALHÃES

Indicações Para uma Reforma Democrática do Poder Judiciário

LUIZ CRUZ DE VASCONCELOS

A Função do Advogado no Estado de Direito.

SÉRGIO BERMUDES

Estado de Direito e Direito de Petição.

ERASMO BARROS DE FIGUEREIDO SILVA

Retorno do Recurso Ordinário no Processo do Mandado de Segurança.

JOAQUIM CORREIA DE CARVALHO JÚNIOR

Estado de Direito e Política Fiscal.

LUCIANO S. CASEIRO

O Alcance da Ação Penal Face à Constituição.

THEREZINHA GODOY ZERBINE

Estado de Direito - Direitos Humanos e a Necessidade de Aristia.

RENE ARIEL DOTTI

A Informação Cultural no Estado de Direito. 
Nota marcante, durante os trabalhos da Conferência, foi a palestra pronunciada pelo Dr. Pontes de Miranda, no auditório da Reitoria, a convite do Centro Acadêmico Hugo Simas. $O$ ato se desenrolou sob a direção do Prof. Fernando Andrade de Oliveira, Procurador Regional da República e presidente do Instituto dos Advogados do Paraná.

\section{$\times \times \times$}

No dia 12 de maio, à noite, nos salões do Clube Curitibano, realizou-se um jantar de confraternização, com a participação de mais de mil e setecentas pessoas, decorrendo a festividade em ambiente de muita alegria e intensa vibração cívica.

Nesse mesmo dia, depois da sessão plenária de encerramento da Conferência no auditório da Reitoria da Universidade Federal, foi colocada uma placa de bronze, alusiva ao certame e com invocação de seus patronos Pimenta Bueno e Hugo Simas, no saguão da Faculdade de Dierito. Usou da palavra, na ocasião, através de improviso, especialmente designado pela OAB do Paraná, o Prof. Desembargador Ary Florencio Guimarães, que sublinhou a importância jurídica e institucional do evento e as figuras exponenciais daqueles eméritos jurispéritos, que em boa hora constituiram o seu símbolo, exortando a mocidade acadêmica para que se aperfeiçoasse cada vez mais pelo estudo, pelo trabalho, e pelo amor à Pátria, em prol do Direito, da Liberdade e da Justiça. A placa foi descerrada, sob palmas dos presentes, pelo Prof. Raymundo Faoro, presidente do Conselho Federal da Ordem dos Advogados do Brasil, a convite do Dr. Eduardo Rocha Virmond, presidente do Conselho Secional do Paraná.

\section{DECLARAÇÃO dOS ADVOGADOS BRASILEROS}

A VII Conferência Nacional da Ordem dos Advogados do Brasil aprovou a seguinte

\section{DECLARAÇÃO DOS ADVOGADOS BRASILEIROS}

Os advogados brasileiros. presentes e representados na VII Conferência Nacional da Ordem dos Advogados, ao reiterarem sua unidade e coesão, trazem sua palavra ao povo, ao qual pertencem e devem conta de suas preocupações e de sua conduta pública. Armados da palavra e da razão, sentem-se credenciados, ainda uma vez dentro da sombra autoritária e que envolve o País, a expressar mensagem de esperança e de liberdade, clamando pelo Estado de Direito democrático. 
O Estado democrático é a única ordem que pode proporcionar as condições indispensáveis à existência do verdadeiro Estado de Direito, onde a liberdade - autonomia cede lugar à liberdade - participação que pressupõe princípios pertinentes ao núcleo das decisões políîicas $\epsilon$ à sua legitimidade institucional. Para isso não basta o voto consentido, pois só ele não constitui a essência da democracia; ao contrário: é a própria democracia que dá conteúdo de participação ao direito de voto. Expressão de ato político e democrático, a vontade que este representa, exige processo normativo integrado, desde a organização pluripartidária - representativa da várias correntes de opinião pública - às garantias da livre manifestação do pensamento, incluido o direito de crítica às instituições. As restrições à liberdade somente se tornam legítimas na medida em que visem à preservação do interesse coletivo - respeitado o limite infraqueável da dignidade da pessoa. O controle judicial, por tribunais dotados das garantias da magistratura, cuidará de remediar qualquer lesão ou ameaça de lesão à liberdade, sintese dos direitos humanos. Os direitos fundamentais não podem sofrer agravo de grupos ou entidades privadas, e, com maior razão, devem ser postos ao abrigo de agressões que decorram das autoridades constituidas, cujo dever primeiro será o de amparar - livre desenvolvmiento daqueles direitos. Se o contrário fosse admissível, reconhecer-se-ia o absurdo da subversão da ordem pelos seus próprios agentes. Essas agressões à dignidade da pessoa não se justificam; ainda quando se dissimulam debaixo do pretexto de segurança nacional. No Estado de Direito, a segurança nacional constitui meio de garantir as liberdades públicas. Protege-se o Estado, para que este possa garantir os direitos individuais. A legitimidade da incriminação de atentados à segurança nacional, repousa no princípio de que só pelos meios jurídicos podem ser alteradas as instituições estabelecidas pelo povo, através de representantes livremente escolhidos. Para que a segurança nacional se enquadre no Estado de Direito, garantindo a inviolabilidade dos direitos do homem, o crime só pode ser definido mediante a tipicidade de fatos externos, ofensivos a bens ou interesses jurídicos. O ilícito penal não compreende, a título de ilícito político, restrições a idéias dissidentes do regime, nem no mero exercício de meios para formá-las. Não haverá Estado de Direito nem segurança nacional democraticamente entendidos, sem a plenitude do habeas corpus que assegure a primeira das liberdades e base de todas as outras - a liberdade física - em regime que consagre a inviolabilidade e a independência dos juízes. O habeas corpus, cuja substância está na sua inteireza, consagra cinco séculos de nossa herança luso-brasileira, herança jurídica, política e moral, que devemos resguardar e transmitir a outras gerações. No Estado de Direito 
as garantias institucionais decorrem da partilha das funções do Estado entre vários poderes, de modo que um não amesquinhe nem anule os outros, mas todos se limitem mutuamente, em sistemas de fiscalização e controle recíprocos. A vigência do Al-5 faz reinar no Brasil uma situação de excepcionalidade, a mais longa da história brasileira, tradicionalmente ferida de temporários colapsos da liberdade. Declaramos, todavia, que a simples revcgação do Al-5 não restauraria, por si só, o Estado de Direito, diante da realidade que a vigente Constituição não forma estrutura política democrática.

Não se negará, dentro do Estado de Direito. a legitimidade de instrumentos que o defendam, ao tempo e na justa medida que defendam a liberdade dos cidadãos.

No caso de grave perturbação da ordem e na eventualidade de guerra externa, dispõe a tradição do direito brasileiro do instituto do estado de sítio, sem que na sua regulamentação se insinuem o arbítrio e a irresponsabilidade. A nação se resguarda pela ação conjunta dos três poderes e, nunca, pela usurpação de um às atribuições dos outros, em velada suspeita da incapacidade destes. Essa a instância máxima das restrições que possam ser impostas ao exercício dos poderes e aos direitos fundamentais. Se o governo deve contar com meios prontos e eficazes para debelar situações excepcionais, serão os estritamente necessários e suficientes, respondendo pelos abusos ou excessos que cometer, quer pela via política, administrativa ou judicial.

No Estado de Direito, a defesa das instituições não legitimaria exclusões, ostensivas ou dissimuladas, da efetiva participação política e social do povo. Cumpre, para suprimir obstáculos arbitrariamente criados, rever a legislação trabalhista do país, de nítida inspiração autoritária. ao ponto de alguns de seus dispositivos violarem a Declaração Universal dos Direitos do Homem. Sem liberdade sindical não pode existir um verdadeiro e autêntico direito coletivo de trabaIho. que encontra nos sindicatos seus sujeitos de direito e seus agentes dinâmicos. Sem liberdade sindical não há democracia possível, não há Estado de Direito. Só o Estado de Direito reconhece os conflitos, legitima-os e os supera. Os direitos políticos. longe de obstarem os direitos sociais, constituem a única via pacífica para a sua obtenção e o seu exercício. Direitos sociais e direitos políticos são o conteúdo do Estado de Direito, que, por ser um Estado ético, repele a idéia da injustiça, situada nas desigualdades decorrentes da excessiva riqueza de uns, da extrema miséria da maioria. Uma política fiscal justa e eficiente há de atenuar essa situação, e, ao tempo em que se volte contra a desigualdade, estará isenta de arbítrio, com a criação de tri- 
butos, seu aumento e discriminação por atos que atendam ao consentimento popular e às normas constitucionais.

Para sua honra, os advogados debatem e estudam a realidade nacional, com a inteligência, o equilíbrio e o senso de responsabilidade que historicamente lhes reconhecem os brasileiros. Identificam no autoritarismo o principal desvio ao livre desenvolvimento da vida jurídica, política e social do país. situam na liberdade de participação a maior preocupação dos seus estudos, participação cuja amplitude exige a pacificação nacional. que lance o esquecimento sobre os ódios do passado. A anistia, embora não leve, por si só, ao Estado de Direito, será passo necessário ao seu aperfeiçoamento. Sabe a Nação que o Estado de Direito, clamor da consciência jurídica do país, não é reivindicação exclusiva de classes ou grupos, mas constitui o necessário pacto de convivência de todos. As promessas governamentais, para que atendam aos reclamos da opinião pública, devem converter-se em ação, com brevidade, em favor da paz e da concórdia dos brasileiros.

Curitiba, 12 de maio de 1978. 